\title{
INTRAVENOUS NITROGLYCERIN CONTROL OF BLOOD PRESSURE DURING RESECTION OF PHAEOCHROMOCYTOMA
}

\author{
W.N. McDonald, W.A. Doll, N. Schmidt and C. Reynolds
}

\begin{abstract}
The majority of patients presenting for resection of phaeochromocytoma require some form of antihypertenive therapy during operation. Phentolamine and sodium nitroprusside have both been used successfully for this purpose, but each has disadvantages. This report describes the use of intravenous nitroglycerin, a rapidly acting venodilator with no appreciable toxicity, as the sole antihypertensive agent in two patients with phaeochromocytoma and partial alpha adrenergic blockade. Hypertensive episodes were quickly and effectively controlled in each case. There were no hypotensive periods and no side effects.
\end{abstract}

KeY WORdS: SURGERY, phaeochromocytoma; Complications, hypertensive crisis, nitroglycerin

ONE OF THE principal objectives in the anaesthetic management of patients undergoing resection of phaeochromocytoma is control of hypertension. These episodes, which are due to catecholamine release from the tumour, occur in a high percentage of cases despite pretreatment with adrenergic blocking agents. Many agents have been advocated for treatment of hypertensive crises during operation, in particular alpha adrenergic blocking agents, ${ }^{1}$ ganglion blocking drugs, ${ }^{2}$ and direct vasodilators such as sodium nitroprusside. ${ }^{3}$ Nitroglycerin administered intravenously is an effective hypotensive agent with a rapid but reversible action and is free of side effects. ${ }^{4}$ To our knowledge, the use of intravenous nitroglycerin has not been described for this purpose. We report experience in two patients with phaeochromocytoma where intravenous nitroglycerin was used for control of blood pressure during operation.

W.N. McDonald, B.Sc., M.D., Resident, Department of Anaesthesia, University of British Columbia, Vancouver, B.C., Canada; W.A. Doll, B.Sc., M.D., F.R.C.P.(C), Clinical Associate Professor, Department of Anaesthesia, University of British Columbia, and Head, Department of Anaesthesia, St. Paul's Hospital, Vancouver, B.C., Canada; N. Schmidt, M.D., M.Sc., F.R.C.S.(C), Clinical Instructor, Department of Surgery, University of British Columbia, Vancouver, B.C., Canada; C Reynolds, B.Sc., M.D., C.M., M.Sc., Assistan Professor, Department of Medicine, University of British Columbia, Vancouver, B.C., Canada.

\section{RePort of Two CASES}

\section{Patient \#1}

A 52 year old man with Von Reckling hausen's disease sought medical attention because of periodic weakness, sweating, and tremulousness following alcoholic binges. $\mathrm{He}$ admitted to experiencing headaches, flushing, palpitations and a $10 \mathrm{~kg}$ weight loss for one year. Physical examination revealed a heavy set man $(103 \mathrm{~kg}, 196 \mathrm{~cm})$ with numerous neurofibromata and cafe au lait spots. Blood pressure was $33.2 / 18.6 \mathrm{kPa}$ (250/140 torr) with a pulse of 140 per minute. There were no significant physical findings apart from grade II hypertensive retinopathy. Routine blood examination, electrocardiogram and chest x-ray were unremarkable. Urinary vanillyl mandelic acid (VMA) was $15 \mathrm{mg}$ per 24 hours (normal 2-7 mg/24 hours) and urinary catecholamine level was $40 \mu \mathrm{g}$ per 24 hours (normal less than $10 \mu \mathrm{g}$ per 24 hours). Abdominal ultrasound and renal arteriograms failed to show any abnormalities but computerized axial tomography revealed a tumour $3 \mathrm{~cm}$ in diameter in the right adrenal gland.

Oral phenoxybenzamine was started on admission and increased to a maximum dose of $40 \mathrm{mg}$ per day. On this regimen blood pressure was maintained around $18.6 / 12.0 \mathrm{kPa}$ (140/ 90 torr), with a slight orthostatic drop. Seven days after admission he was taken to the operating room. The final dose of phenoxybenzamine being given 12 hours before the operation. 
Pre-medication consisted of morphine $15 \mathrm{mg}$ given intramuscularly one hour before operation. On arrival in the operating theatre the patient was calm and the blood pressure was $23.9 / 10 \mathrm{kPa}(180 / 75$ torr $)$. Innovar $2 \mathrm{ml}$ was administered intravenously without any substantial change in blood pressure. An infusion of nitroglycerin in saline $\left(32 \mathrm{ng} \cdot \mathrm{ml}^{-1}\right)$ was started and an intra-arterial line was established in the left radial artery. When the blood pressure resembled that recorded at the pre-operative visit, anaesthesia was induced with thiopentone $425 \mathrm{mg}$ and pancuronium bromide $7 \mathrm{mg}$. Following tracheal intubation a central venous catheter was inserted into the right internal jugular vein. Mild increases in blood pressure caused by these maneouvers were easily controlled by increasing the infusion of nitroglycerin. Anaesthesia was maintained with enflurane (0.5-1.0 MAC), nitrous oxide: oxygen (60:40) and fentanyl $(275 \mu \mathrm{g}$ total).

Blood pressure was smoothly maintained throughout the procedure by varying the rate of nitroglycerin infusion and the concentration of enflurane. Blood pressure remained below $18.6 \mathrm{kPa}$ (140 torr) systolic except for one hypertensive peak of $28.6 / 17.3 \mathrm{kPa}$ (215/130 torr) on manipulation of the adrenal gland. This episode was controlled in less than 90 seconds by increasing the rate of nitroglycerin infusion. Intravenous propranalol $0.5 \mathrm{mg}$ was also given at this time to control tachycardia of 130 /minute. There were no serious "overshoots" while employing the nitroglycerin infusion, the lowest blood pressure recording before removal of the tumour being $12 / 6.6 \mathrm{kPa}$ ( $90 / 50$ torr). A total of $4.83 \mathrm{mg}$ nitroglycerin was administered over a period of 130 minutes. Nitroglycerin infusion was discontinued with removal of the right adrenal gland and was not required thereafter.

\section{Patient \#2}

A 22 year old male presenting with a three month history of fatigue, weight loss, and diaphoresis was found to be hypertensive (26.6/14.6 kPa - 200/110 torr). Further examination revealed a well built young man $(68 \mathrm{~kg}$, $170 \mathrm{~cm}$ ) with a pulse of $110 /$ minute, normal optic fundi, and a grade IVVI flow murmur. Routine blood examination, electrocardiogram and chest $x$-ray were unremarkable. Determination of urinary VMA and catecholamines revealed elevated levels of $41.6 \mathrm{mg}$ per 24 hours and $173 \mu \mathrm{g}$ per 24 hours, respectively.
Computerized axial tomography revealed a 6.7 by 5 centimeter right suprarenal lesion.

Oral phenoxybenzamine was started upon confirmation of the diagnosis and on $40 \mathrm{mg} /$ day his blood pressure was reduced to $18.6 / 11.3 \mathrm{kPa}$ (140/85 torr) supine and $11.3 / 8 \mathrm{kPa}(85 / 60$ torr) standing. Intravascular volume was expanded with two units of packed red cells and six units of stored plasma. He was operated upon one week later. The last dose of phenoxybenzamine was given 12 hours before operation.

Premedication consisted of oxazepam $15 \mathrm{mg}$ orally and meperidine $75 \mathrm{mg}$ intramuscularly, one hour before operation. On arrival in the operating theatre he was calm and his blood pressure was $20 / 8.6 \mathrm{kPa}$ (150/85 torr). Fentanyl $100 \mu \mathrm{g}$ was administered intravenously and an infusion of nitroglycerin $\left(32 \mathrm{mg} \cdot \mathrm{ml}^{-1}\right)$ was started. An intra-arterial line was established in the left radial artery under local anaesthesia. Nitroglycerin was infused until the blood pressure fell to preoperative levels. Anaesthesia was then induced with thiopentone $450 \mathrm{mg}$ and pancuronium bromide $7 \mathrm{mg}$. The arterial pressure suddenly rose to $26.6 / 17.3 \mathrm{kPa}(200 / 130$ torr) but was controlled in less than 60 seconds by increasing the rate of nitroglycerin infusion and starting enflurane (1 MAC). Laryngoscopy and tracheal intubation were carried out three minutes later with only minimal increase in blood pressure. A central venous catheter was then inserted into the right internal jugular vein.

Anaesthesia was maintained with enflurane (0.5-1.0 MAC), nitrous oxide: oxygen (60:40) and fentanyl $(150 \mu \mathrm{g}$ total). Nitroglycerin was infused throughout the procedure $(17.6 \mathrm{mg}$ total) until the right adrenal gland had been removed. Blood pressure did not rise above $18.6 / 12 \mathrm{kPa}$ (140/90 torr) except on one occasion when the adrenal gland was manipulated vigourously. This exacerbation was controlled in less than 90 seconds by increasing the nitroglycerin infusion. The lowest arterial pressure recorded was $12 / 6.6 \mathrm{kPa}$ (90/50 torr). No drugs other than those mentioned were required before reversal of muscle relaxation.

\section{Discussion}

Preoperative preparation of patients with adrenergic blocking agents is regarded as the major factor in the reduction of morbidity associated with resection of a phaeochromocytoma. ${ }^{5}$ The $\alpha$-blocking agent most commonly employed is 
phenoxybenzamine with a duration of action of 24-48 hours. ${ }^{6}$ Alpha blockade minimizes abrupt variations in arterial pressure both before and during operation and allows volume expanding fluids to be infused before removal of the tumour. Alpha blockade and volume expansion may reduce the incidence of hypotension following tumour removal.

Complete $\alpha$-adrenergic blockade is difficult to achieve and most patients present for operation with incomplete blockade. Some authors ${ }^{7}$ advocade incomplete $\alpha$-blockade, as complete blockade may mask sudden arterial pressure changes with tumour palpation, thus hindering localization of ectopic tumours. However, incomplete $\alpha$-blockade renders patients vulnerable to hypertensive crises during operation.

Various types of drugs have been advocated for treatment of hypertensive crises during operation for phaeochromocytoma. Phentolamine has been the drug most commonly used for this purpose because of its $\alpha$-blocking action. However, its use may be accompanied by significant tachycardia, cardiac stimulation, and arrythmias. These effects appear to be due to pre-synaptic stimulation and uninhibited release of noradrenaline, an effect attributed to blockade of postulated $\alpha_{2}$ receptors. $^{8}$ Tachyphylaxis has also been described. ${ }^{9}$ An additional problem is the duration of action of phentolamine, which may exceed that of the hypertensive episode.

Sodium nitroprusside is an extremely short acting antihypertensive agent. Its potency and rapid onset and termination of effect render it highly effective for control of hypertension during operation. Because of its potency and rapid action there may be uncontrolled lowering of blood pressure. While the potential for cyanide toxicity does exist, this is not a problem with the doses commonly used for this operation. Sodium nitroprusside must be administered in foil wrapping to prevent degradation in light.

Intravenous nitroglycerin is less potent than sodium nitroprusside but is, nevertheless, an effective and rapidly acting antihypertensive agent. It is virtually devoid of side effects and is very easy to use. Commercial preparations have a shelf-life of up to six months ${ }^{10}$ and it does not require protection from light while in use. It exerts its effects mainly on capacitance vessels, ${ }^{4}$ independent of $\alpha$ receptors. For these reasons intravenous nitroglycerin was used in the anaesthetic management of two patients undergoing resection of phaeochromocytoma and its suit- ability as an alternative to sodium nitroprusside was assessed.

Nitroglycerin infusion was started before induction of anaesthesia and it was infused throughout the procedure, the rate being titrated against the arterial pressure. Alpha blockade was incomplete in both patients as evidenced by several hypertensive episodes in each case. Arterial pressures were smoothly maintained in both patients and hypertensive exacerbations responded within 90 seconds in each case. There were no hypotensive overshoots and no unwanted side effects.

Based on this limited experience, intravenous nitroglycerin appears to be a suitable alternative to sodium nitroprusside for the control of blood pressure during resection of phaeochromocytoma in patients with partial $\alpha$-blockade. It has the advantages of being effective, fast acting, easy to control, and free of side effects.

\section{REFERENCES}

1. Brunjes, S., Johns, V.J. \& Crane, M.G Pheochromocytoma-Postoperative shock and blood volume. N. Eng. Jour. Med. 262: 393 (1960).

2. Stamenkovic, L. \& Spierdijk, J. Anaesthesia in patients with pheochromocytoma. Anaesthesia 31: 941 (1976).

3. Tinker, J. H. \& Michenfelder, J.D. Sodium Nitroprusside: Pharmacology, Toxicology and Therapeutics. Anesthesiology 45: 340 (1976).

4. FAHMY, N.R. Nitroglycerin as a hypotensive drug during general anaesthesia. Anesthesiology 49: 17 (1978).

5. Desmonts, J.M., Le Houelleur, J. Remond, P. \& DuRALDEsTiN, P. Anaesthetic management of patients with phaeochromocytoma. Brit. Jour. Anaes. 49: 991 (1977).

6. Perry, L.B. \& Gould, A.B. The anesthetic management of phaeochromocytoma: Effect of preoperative adrenergic blocking drugs. Anesth. Analg. 51:36 (1972).

7. Harrison, T.S., Bartlett, J.D. \& Seaton, J.F. Current evaluation and management of pheochromocytoma. Ann. Surg. 168: 701 (1968).

8. Hoffman, B.B. \& Lefkowitz, R.J. Alphaadrenergic receptor sub-types. N. Eng. Jour. Med. 302: 1390 (1980).

9. El-NaGger, M., Suerte, E. \& Rosenthal, E. Sodium nitroprusside and lidocaine in the anaesthetic management of pheochromocytoma. Can. Anaesth. Soc. J. 24: 353 (1977).

10. Omega Pharmaceuticals. Montreal, Quebec. Personal communication, 1981. 


\section{RÉSUMÉ}

La majorité des malades qui se présentent pour une résection de phéochromocytome a besoin d'une forme ou d'une autre de thérapie antihypertensive pendant la chinurgie. La phentolamine et le nitroprussiate de sodium ont été utilisés avec succès à cette fin mais ces deux médicaments ont des inconvénients. Les auteurs rapportent l'emploi de nitroglycérine intraveineuse, agent vasodilatateur à action rapide et non toxique, comme seul agent antihypertenseur chez deux patients porteurs de pheochromocytomes et chez qui on avait administré des alpha-bloqueurs. Les épisodes hypertensifs ont été rapidement et effectivement contrôlés et il n'y a pas eu d'épisodes hypotensifs, ni d'effets secondaires. 